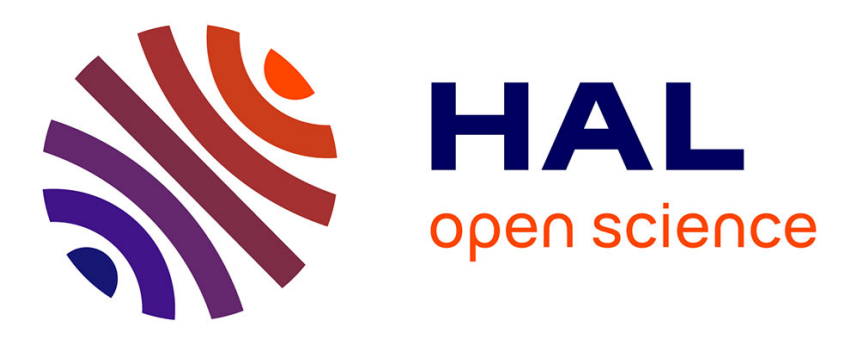

\title{
Medical Supplies to the Point-Of-Use in Hospitals
}

Giuseppe Ismael Fragapane, Aili Biriita Bertnum, Hans-Henrik Hvolby, Jan

Ola Strandhagen

\section{To cite this version:}

Giuseppe Ismael Fragapane, Aili Biriita Bertnum, Hans-Henrik Hvolby, Jan Ola Strandhagen. Medical Supplies to the Point-Of-Use in Hospitals. IFIP International Conference on Advances in Production Management Systems (APMS), Sep 2019, Austin, TX, United States. pp.248-255, 10.1007/978-3030-29996-5_29. hal-02460525

\section{HAL Id: hal-02460525 \\ https://hal.inria.fr/hal-02460525}

Submitted on 30 Jan 2020

HAL is a multi-disciplinary open access archive for the deposit and dissemination of scientific research documents, whether they are published or not. The documents may come from teaching and research institutions in France or abroad, or from public or private research centers.
L'archive ouverte pluridisciplinaire HAL, est destinée au dépôt et à la diffusion de documents scientifiques de niveau recherche, publiés ou non, émanant des établissements d'enseignement et de recherche français ou étrangers, des laboratoires publics ou privés.

\section{(c)(1)}

Distributed under a Creative Commons Attribution| 4.0 International License 


\title{
Medical supplies to the Point-Of-Use in hospitals
}

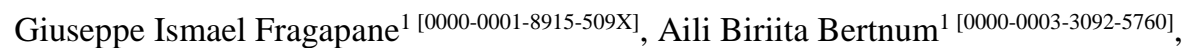 \\ Hans-Henrik Hvolby ${ }^{1,2}$ and Jan Ola Strandhagen ${ }^{1}$ [0000-0003-3741-9000] \\ ${ }^{1}$ Department of Mechanical and Industrial Engineering, Norwegian University of Science and \\ Technology, 7491 Trondheim, Norway \\ ${ }^{2}$ Centre for Logistics, Department of Materials and Manufacturing Engineering, \\ Aalborg University, Denmark \\ \{giuseppe.fragapane, aili.b.bertnum, hans.h.hvolby, \\ ola.strandhagen\} antnu. no
}

\begin{abstract}
In order to match financial sustainability with the delivery of highquality healthcare hospitals need to seek efficient ways of managing inventories with a large variety of medical supplies. To find a balance in the trade-off between cost and service levels that ensures on time and high-quality patient treatment is a challenge. It is especially crucial in the hospital setting, where the consequence of a stock-out can be much more severe than lost revenue. The process of ensuring that the required supplies are available at the right time is a particularly important supporting role within hospital logistics. The scope of this study is inventory control at the point-of-use inventories in hospitals. It concerns the short-term planning and control area, which focus on coping with actual demand and making necessary changes in order to match efficiently to plans. This study aims to model the inventory control process and discuss how technology can support high availability of medical supplies in hospitals.
\end{abstract}

Keywords: Inventory control, Point-of-use, Hospital.

\section{Introduction}

New medical advances broaden the spectre of possible treatments and the patients have higher expectations to the quality of treatment than ever [1,2]. The trend of increasing demand in hospitals is accompanied by increasing shortages of doctors, nurses and supporting staff [3]. In addition, healthcare expenditures represent an increasing share of the economy in most OECD countries [2]. The cost of supplies and services are starting to outpace hospital budgets. In order to match financial sustainability with the delivery of high-quality healthcare hospitals need to seek efficient ways of managing inventories with a large variety of medical supplies $[4,5]$.

Several challenges are present in the processes of inventory control in hospitals. Hospitals experience unpredictable demand and large varieties in the supply consumption due to varying patient mix. Fluctuating demand is especially present in the emergency department in which patients have not scheduled treatments. Hospitals need to 
keep an extensive number of stock keeping units (SKUs) to be prepared to treat a variety of illnesses. The variety is even further increased by individual physicians' preferences regarding specific brands of equipment or consumables they prefer using.

Traditionally, there are at least two levels of inventory in the hospital supply chain, a central warehouse and point-of-use (POU) inventories. The POU inventories are generally characterized by lack of space to store the different medical supplies needed at the point-of-care. The space restrictions combined with fluctuating demand and a large amount of different SKUs lead to the need for efficient control of available inventories. Though slightly neglected in the past, inventory management in hospitals has in recent years been recognized as one key lever towards realizing efficiency improvements with regards to cost and waste, while at the same time satisfying service levels [6]. To find a balance in the trade-off between cost and the service levels that ensures on time and high-quality patient treatment is a challenge. It is especially crucial in the hospital setting, where the consequence of a stock-out can be much more severe than lost revenue [7]. The process of ensuring that the required supplies are available at the right time is a particularly important supporting role of hospital logistics.

The study concerns the short-term planning and control area, which focus on coping with the actual demand and making the necessary changes in order to match efficiently to plans [8]. The objective of this study is to investigate the challenges of inventory control in hospitals and discuss how technology can support high availability of medical supplies. The inventory control processes in hospitals will also be visualised, showing the interdependencies between the internal and external hospital supply chain.

The rest of this study is organized according to the following structure. Section 2 embodies the literature on inventory control in general, specific inventory control policies and their application in an overall inventory control system. Section 3 describes the inventory control processes of an emergency department at a large hospital in Norway, which serves as input to the following section. Section 4 discusses the different review policies in hospitals and enablers with the use of technology for inventory control. The study is concluded with a summary of major insights and an outline of future research.

\section{Theoretical background}

Inventory control is based on answering the questions of what to order, how much to order and when to order [9]. It entails both controlling the inventory in form of on-hand physical inventory, as well as record counts and monetary worth [10]. The demand is hard to predict and there is lack of information on the consumption of supplies from the POU inventories [7]. Non-availability of supplies may result in postponement of surgeries, and can in the worst case be critical to a patient's life. On the other side, overstocking or hidden stocks lead to supply chain inefficiencies and higher inventory costs [11].

Demand for items of POU inventories can be characterized as independent. Demand of a product is independent when it is influenced by conditions outside the control of 
the organization, rather than being dependent on another product [10]. With independent demand, efforts must be made to match the inventory with demand based on historical demand, forecasts and "best guesses", while still be prepared to respond quickly when mismatches occur [8]. According to Muller [10], independent demand calls for a replenishment approach to inventory management, where stock is replenished as it is used, in order to have items on hand to fulfill demand.

The decisions on how much to order and when to order are closely linked. How much to order depends on the frequency and time in which orders are placed, in the same way as when to order depends on the volumes ordered. In order to control inventories, a policy that is simple and efficient to use is of importance. The policy needs to be combined with supporting identification technologies to decrease the response time. The choice of suitable inventory (replenishment) policy, is a widely discussed topic within the area of hospital inventory management [6]. Traditionally, the choice of inventory policy concerns deciding the suitable inventory review cycle and reorder quantity [6].

The review cycle can be either periodic or continuous. Slack [8 p.707] defines the periodic review as "an approach to making inventory decisions that define points in time for examining inventory levels and making decisions accordingly". Points in time can be e.g. on a daily or weekly basis. Continuous review is defined as "an approach to managing inventory that makes inventory-related decisions when inventory reaches a particular level" [ $8 \mathrm{p} .702]$. The review policy requires continuous tracking of inventory levels. The review cycle must be determined based on variability in demand and costs of ordering, holding and delivering supplies [12].

The periodic review seems to be most commonly used in hospitals today, although some argue that continuous review is superior to periodic review [7]. This is due to the ability of continuous review to provide real-time updates on inventory levels by the use of data capturing technologies. Çakıcı et al. [13] argue that in cases where real-time information is made available without large additional cost, the continuous review is superior to periodic review. E.g., the use of RFID allows for a continuous review policy instead of the typically utilized periodic review [14].

The number of shipments is expected to be higher with a continuous review policy than with a periodic review policy. This results in the continuous review being most convenient when the cost per shipment is low. However, with a period review policy it is easier to incorporate different orders in the same shipment, which will save transportation costs. The traditional periodic review policies applied in hospitals are being replaced with continuous or hybrid review policies (periodic-continuous) enabled by modern point-of-use technology, such as automated dispensing cabinet and two-bin systems in combination with RFID [15].

Inventory control systems, also called replenishment systems or distribution systems, describe how inventory control policies are applied in practice. It defines how inventories are intentionally organized and combined with enabling identification technologies in order to enable different inventory control policies. Several methods have been applied and discussed in the literature on how to control and distribute supplies from the central warehouse to POU in hospitals [16]. 
The variation of methods and inventory policies have an impact on the degree of staff involvement. The replenishment responsibility either is centralized to the logistics department or decentralized to the staff at the POU locations. The range of methods applied at POU inventories varies from manual systems like the requisition based system or exchange carts, which are rarely used today, to commonly used systems such as Periodic Automatic Replacement (PAR) or two-bin systems enabled by barcode or RFID technology.

\section{Case study}

\subsection{Methodology}

The case study was carried out with a large Norwegian hospital that treats 60'000 inpatients (patients who stay overnight in the hospital during treatment) and 370'000 outpatients (patients who visit the hospital for treatment without staying overnight) yearly. The hospital has 800 beds, 8000 employees and an annual budget of 8.2 billion NOKs [17]. The purpose of the case study was to get a holistic view of the logistic processes at a hospital in practise, and more specifically the process of inventory control at the POU inventories in the emergency department subject to fluctuating demand. The advantage of a single case study is to analyse the phenomena in greater depth [18].

Empirical data was collected through semi-structured interviews, observations, and information retrieved from field documents. Multiple semi-structured interviews were conducted both on-site and through meetings. The purpose was to interview key personnel able to provide solid descriptions of the processes inside and outside the hospital. Interviews were conducted with both a warehouse manager, purchaser, logistics manager at the hospital and a porter from the emergency \& cardiothoracic centre.

A semi-structured interview is a flexible interview technique consisting of a set of predefined questions while allowing for open-ended exploration and deflection from the predefined questions [19]. In preparation of the interviews, a brief interview guide was prepared, consisting of the purpose of the study and topics to be covered in the interview, as well as suggested questions. During the interviews, most of the topics were covered and additional information was collected. Based on notes made during interviews, reports were formulated as documentation.

\subsection{Materials ordering flow}

The case hospital utilizes periodic review and order-up to level as the inventory control policy. The current inventory level is decided by roughly estimating the inventory levels of the different products. However, the input provided to the handheld computer is not a count of the current levels of inventory, but rather a direct input on the quantity wished to be replenished.

The disturbances that can occur during the periodic measure and order of inventory level is a combination of human and technological errors. It is up to human accuracy to scan the right barcodes, give the correct input on order quantity and make sure that 
every room, cabinet, and shelves are checked each round. If the order is not sent according to the schedule provided, it is also a human error. Additionally, the handheld computers are quite old, and the software operates slowly, which sometimes leads to technical errors such as hang-ups or that the computer fails to scan the barcode.

The deadline for sending the order is 8:30 AM. Once the orders are sent, there is a leadtime of 2 hours (8:30-10.30AM) on replenishment between the central warehouse and goods reception in the hospital. As all supplies are delivered to the good reception at once, queues in AGV transportation often occurs. Therefore, the supplies are normally not available at the POU before around 12.00 PM. An additional disturbance to the system regarding the replenishment of supplies is observed. Several times a week the hospital get wrong quantities or products delivered. This could be due to technological or human errors in the ordering process at the POU, or by wrongful picking of orders at the central warehouse.

The overall processes of inventory control from the central warehouse to POU in the case hospital are visualised in Fig. 1. The external supply processes are visualised in the top timeline, while the internal inventory control processes are visualised in the bottom timeline. T1, T2, and $\mathrm{T} 3$ represent the scheduled transportation of goods deliveries by trucks from the central warehouse to the hospital.

Central warehouse
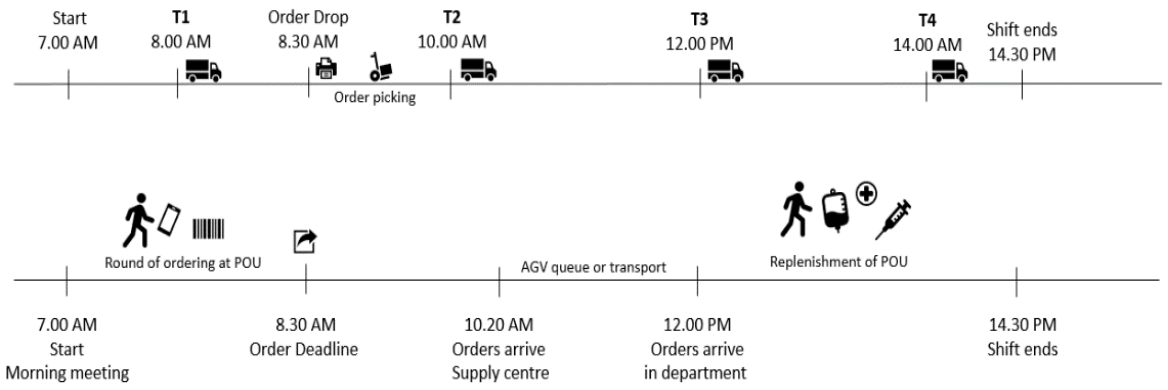

Fig. 1. The inventory control process in the case hospital

\section{Discussion}

Due to the demand patterns found in the emergency department (especially on a busy night) stock-outs can easily occur in between the periodic reviews of inventory. With the characteristics of demand at emergency departments, literature states that the continuous review policy is a more suitable method. New technologies enabling real-time inventory records, visibility of material flows, as well as automated order generation are already available. RFID is an enabler of continuous review that has been given attention within the field of hospital inventory management. However, hospitals have not 
adopted the technology as fast as in other industries. Different inventory control policies and technologies are combined with replenishment systems that control the POU inventories. The descriptive control model in Fig. 1 serves to describe the POU inventory system and support to discuss how different technological solutions support the availability of medical supplies.

The storage area is very limited in the emergency department at the case hospital, meaning that not all supplies can be stored in the common two-bin systems. With a limited storage capacity, the availability of items becomes more dependent on the responsiveness of the overall supply chain. The study by Little and Coughlan [20] shows that optimizing inventory within space constrictions requires more frequent deliveries of supplies to keep high service levels. This implies using continuous review solutions and quick replenishment systems, by either employing extra labour or implementing technological solutions. The inventory control system can support in identifying and mapping the current state of the replenishment and inventory control process. Modelling the process provides a visualization of the different flows, input and output controlling the inventory level. This can support to decide for a suitable technological solution within the internal hospital supply chain.

One of the strengths of the inventory control system at the case hospital is the central warehouse's quick response to signal and demand, and the use of order-up-to levels to decide order quantities. This solution is appropriate and efficient for limited storage space, while still providing high service levels [21]. The responsibility and time consuming task of monitoring inventory and supplies have been outsourced from the nurses to a small group of porters. However, stock-outs and unavailability of medical supplies are unavoidable and occur weekly in the emergency department. Stock-outs can occur especially quickly in situations where several patients are treated at the emergency department due to e.g. a car crash.

With the implementation of technologies for the inventory control processes, it can support the external supply processes by providing better visibility of the inventory. With this information, the supply chain can adjust its efforts towards being more responsive to changing demand. The use of real-time information of inventory levels can be an enabler for increased responsiveness in the overall supply chain, which can result in the possibility of having better availability of a broader range of SKUs, while keeping smaller quantities of the SKUs at POU inventories in the hospital. In an emergency department, this can prove to be especially valuable due to its characteristics of fluctuating and emergent demand.

\section{$5 \quad$ Conclusion and further research}

Most hospitals have limited storage space at the POU and an increasing variety of SKUs. This provides challenges when it comes to the availability of medical supplies. Every hospital has its own individual supply chain capabilities and configurations, and space restrictions when it comes to the storage area. The infrastructure can be new or 
old, and the degree of technology advancement varies. This has led to a range of different ways to control POU inventories. In the case hospital, the handheld computers used for ordering are old and can cause several types of errors.

The literature has highlighted the use of periodic review in combination with either fixed quantity or order-up-to level as the traditional inventory control policy applied at POU inventories in hospitals. However, this may not be a robust enough control policy if the goal is to assure availability. The policy gives poor stock visibility in between the periodic review and lack of real-time inventory data. The case hospital experience often that the wrong quantity or product is delivered from the central warehouse. By improving stock visibility and using real-time inventory data when ordering it can be assumed that such errors can be reduced or even eliminated.

Different inventory control policies are being applied in combination with various supporting technologies, to form the replenishment systems of the POU-inventories. The inventory control process has been mapped and visualised. In order to improve the visibility of the inventory levels new replenishment systems have been introduced. One can conclude with the fact that ensuring availability of medical supplies needs a joint effort from both the supply chain and the inventory control processes. Identification technology such as RFID has shown great potential to enable continuous real-time tracking of inventory levels and automatic order generation. Several barriers are present for the successful implementation of these solutions in the hospitals. Continuous improvements in both areas, in combination with the possibilities implied by emerging technologies, can change the design of the inventory control process towards a state were better availability of medical applies could be ensured.

Future research should focus on how different technological solution and hospital supply chain configuration have an impact on the response time and inventory efficiency.

\section{Acknowledgement}

This research received funding from the strategic research area NTNU Health in 2019 at NTNU, Norwegian University of Science and Technology. The authors also gratefully acknowledge the case hospital that made it possible to carry out this study and Elise Keseler, master student at NTNU, for supporting this research.

\section{References}

1. Bacik, J., et al., Pathfinder-Development of Automated Guided Vehicle for Hospital Logistics. Ieee Access, 2017. 5: p. 26892-26900.

2. OECD, Health at a Glance 2017. 2017.

3. Bendavid, Y., H. Boeck, and R. Philippe, RFID-Enabled Traceability System for Consignment and High Value Products: A Case Study in the Healthcare Sector. Vol. 36. 2011. 3473-89.

4. Rosales, C.R., M. Magazine, and U. Rao, The 2Bin system for controlling medical supplies at point-of-use. European Journal of Operational Research, 2015. 243(1): p. 271-280. 
5. Papanicolas, I. and P. Smith, Health System Performance Comparison : An Agenda for Policy, Information and Research. 2013, Maidenhead: McGraw-Hill Education.

6. Volland, J., et al., Material logistics in hospitals: A literature review. Omega-International Journal of Management Science, 2017. 69: p. 82-101.

7. Moons, K., G. Waeyenbergh, and L. Pintelon, Measuring the logistics performance of internal hospital supply chains - A literature study. Omega, 2019. 82: p. 205-217.

8. Slack, N., Operations management. 7th ed. ed, ed. A. Brandon-Jones and R. Johnston. 2013, Harlow: Pearson Education.

9. Waters, C.D.J., Inventory control and management. 2nd ed. ed. 2003, Chichester: Wiley.

10. Muller, M., Essentials of Inventory Management. 2011, Saranac Lake, UNITED STATES: AMACOM.

11. de Vries, J., The shaping of inventory systems in health services: A stakeholder analysis. International Journal of Production Economics, 2011. 133(1): p. 60-69.

12. Rossetti, M.D., N. Buyurgan, and E. Pohl, Medical Supply Logistics, in Handbook of Healthcare System Scheduling, R. Hall, Editor. 2012, Springer US: Boston, MA. p. 245-280.

13. Çakıcı, Ö.E., H. Groenevelt, and A. Seidmann, Using RFID for the management of pharmaceutical inventory - system optimization and shrinkage control. Decision Support Systems, 2011. 51(4): p. 842-852.

14. Paltriccia, C. and L. Tiacci, Supplying networks in the healthcare sector: A new outsourcing model for materials management. Industrial Management \& Data Systems, 2016. 116(8): p. 1493-1519.

15. Rosales, C.R., Technology Enabled New Inventory Control Policies in Hospitals. 2011, University of Cincinnati.

16. Landry, S. and M. Beaulieu, The Challenges of Hospital Supply Chain Management, from Central Stores to Nursing Units, in Handbook of Healthcare Operations Management: Methods and Applications, B.T. Denton, Editor. 2013, Springer New York: New York, NY. p. 465-482.

17. Nedland, S.M., Avanserte logistikklфsninger på St. Olavs Hospital. 2015.

18. Voss, C., M. Frohlich, and N. Tsikriktsis, Case research in operations management. International Journal of Operations \& Production Management, 2002. 22(2): p. 195-219.

19. Wilson, C., Chapter 2 - Semi-Structured Interviews, in Interview Techniques for UX Practitioners, C. Wilson, Editor. 2014, Morgan Kaufmann: Boston. p. 23-41.

20. Little, J. and B. Coughlan, Optimal inventory policy within hospital space constraints. Health Care Management Science, 2008. 11(2): p. 177-183.

21. Bijvank, M. and I.F.A. Vis, Inventory control for point-of-use locations in hospitals. Journal of the Operational Research Society, 2012. 63(4): p. 497-510. 